DOI: https://doi.org/10.47405/mjssh.v5i12.601

\begin{tabular}{|c|c|}
\hline 8 & Malaysian Journal of Social Sciences and Humanities (MJSSH) \\
\hline Malaysian Journal of & Volume 5, Issue 12, December 2020 \\
\hline (MJ-sSH) & e-ISSN : 2504-8562 \\
\hline & $\begin{array}{l}\text { Journal home page: } \\
\text { www.msocialsciences.com }\end{array}$ \\
\hline
\end{tabular}

\title{
Hubungan antara Kemahiran Membuat Keputusan dan Daya Tahan dalam kalangan Pelajar Pintar Berbakat
}

\author{
Nor Hamizah bt Ab Razak¹, Abdul Rashid Aziz @ Dorashid'1, Nurhafizah Mohd Sukor1 \\ ${ }^{1}$ Fakulti Kepimpinan dan Pengurusan, Universiti Sains Islam Malaysia (USIM) \\ Correspondence: Nor Hamizah bt Ab Razak (norhamizah@usim.edu.my)
}

\begin{abstract}
Abstrak
Isu sosial dan emosi dan pelajar pintar berbakat (PPB) tidak dapat dipisahkan. Bimbingan bagi menguruskan isu sosial dan emosi dalam kalangan PPB sangat penting untuk membantu perkembangan pelajar secara optimum serta merangsang kecemerlangan negara. Kajian ini adalah bertujuan untuk mendedahkan mengenai keperluan meningkatkan kemahiran membuat keputusan dan daya tahan dalam kalangan PPB yang juga merupakan pendekatan yang berstrategik bagi membantu golongan ini menguruskan isu sosial dan emosi. Dalam pada itu, kaunselor merupakan agen yang tepat dan perlu memainkan peranan penting dalam membantu PPB meningkatkan kemahiran dan kebolehan tersebut seterusnya membantu mereka menangani isu sosial dan emosi.
\end{abstract}

Kata kunci: pelajar pintar berbakat, sosial dan emosi, kemahiran membuat keputusan, daya tahan

\section{The Relationship between Decision Making Skills and Resilience among Gifted and Talented Students}

\begin{abstract}
Social and emotional issues among gifted and talented students (GTS) are inseparable. Guidance to manage social and emotional issues among GTS is very important to help students' optimal development and stimulate national excellence. This study aims to reveal the need to improve decisionmaking skills and resilience among GTSs which is also a strategic approach to help these groups manage social and emotional issues. In the meantime, counsellors are the right agents and should play an important role in helping GTS improve their skills and abilities and help them deal with social and emotional issues.
\end{abstract}

Keywords: gifted and talented students, social and emotional issue, decision making skills, resilience

\section{Pengenalan}

Secara umumnya, pelajar pintar dan berbakat (PPB) adalah individu yang memiliki kelebihan dari aspek perkembangan seperti fizikal, psikomotor, emosi, spiritual, intelek dan juga sosial jika dibandingkan dengan pelajar biasa (Touron, Touron \& Silvero, 2005). Di Malaysia, PPB dikenal pasti 
melalui program Permata Negara iaitu program yang merangka konsep pelajar pintar dan berbakat selaras dengan matlamat Falsafah Pendidikan Kebangsaan Negara iaitu menjadi tunggak dalam pembentukan modal insan negara (Siti Fatimah et al. 2012). Begitu juga di negara lain di seluruh dunia yang memiliki kaedah tersendiri dalam mengenal pasti aset negara tersebut. Walaupun golongan ini lebih dikenali sebagai individu yang memiliki kecemerlangan intelek, kreativiti serta kecekapan menyelesaikan masalah yang tinggi (Rorlinda, 2014; Renzulli, 1978) namun, mereka juga bergelut dengan isu sosial dan emosi (Versteynen, 2013; Rosadah et al., 2009; Abu Yazid \& Aliza, 2009; Aliza \& Hamidah, 2009) yang menjadi penghalang bagi mereka untuk berkembang secara optimum.

Kajian dari dalam dan luar negara telah mendedahkan isu-isu sosial dan emosi dalam kalangan PPB adalah seperti masalah ketegangan emosi (emotional intensity), amat mementingkan kesempurnaan (perfectionism), kebimbangan yang tinggi, sensitiviti yang tinggi, keterujaan yang melampau (overexcitability), kepekaan terhadap keadilan sosial yang tinggi, kritik diri yang tinggi, sukar mengadaptasi ke suasana yang baharu, dan kurang kemahiran penyesuaian sosial dan komunikasi (Abu Yazid \& Noriah, 2016; Fouladchang, Kohgard \& Salah 2010; Mofield, 2010; Rosadah et al, 2009). Seterusnya, menurut Scott (2012), Abu Yazid \&Aliza (2009) dan Aliza \& Hamidah (2009) pula keadaan tersebut dikatakan timbul berpunca daripada faktor-faktor seperti perkembangan yang tidak sekata (asynchronous), jangkaan tinggi daripada pelbagai pihak, pembelajaran tidak mencabar yang sering membosankan, kesukaran menyesuaikan diri dalam interaksi sosial dan sebagainya. Isu-isu tersebut didapati boleh menyumbang kepada permasalahan rasa rendah diri, rendah motivasi kendiri, pencapaian bawah tahap (underachievement) dan kebimbangan (Rorlinda et al., 2016).

Perkara di atas menjelaskan isu sosial dan emosi memberi pengaruh yang besar kepada perkembangan PPB dari aspek kesihatan mental dan juga kebolehan akademik. Oleh itu, PPB memerlukan pengetahuan, kemahiran serta kebolehan yang sesuai sebagai langkah yang berstrategik dalam menangani isu sosial dan emosi yang dihadapi (Java, 2014; Mann, 2006). Dalam mengendalikan isu tersebut, kemahiran membuat keputusan dan daya tahan dilihat sebagai elemen yang tepat untuk dipertingkatkan dalam kalangan mereka. Ini kerana, kemahiran dan kebolehan tersebut mempunyai perhubungan di antara satu sama lain (Coscun et al, 2014) dan sangat dituntut dalam mengendalikan isu sosial dan emosi (Cazan \& Dumitrescu, 2016). Oleh itu, dengan memiliki kemahiran membuat keputusan dan daya tahan memberikan implikasi yang besar kepada PPB iaitu dapat menangani isu sosial dan emosi seterusnya berkembang pada tahap yang optimum.

Dalam pada itu, Colengelo (2002) mencadangkan agen utama yang penting dalam membantu PPB adalah kaunselor terutamanya kaunselor di sekolah. Menurut beliau lagi, melihat kepada peranan kaunselor itu sendiri, mereka memiliki kelayakan yang memenuhi syarat dalam memberi perkhidmatan kepada pelajar. Selain itu, mereka juga adalah terlatih untuk melaksanakan program pengembangan yang komprehensif yang mampu meningkatkan pencapaian serta menyediakan bimbingan dari segi kerjaya, akademik dan juga isu personel. Justeru, adalah menjadi tugas kaunselor dalam membantu meningkatkan lagi kemahiran membuat keputusan dan daya tahan dalam kalangan PPB. Antara pendekatan yang boleh dilaksanakan oleh kaunselor adalah dengan memberikan perkhidmatan bimbingan dan kaunseling (Noriah \& Yazid, 2010).

\section{Objektif Kajian}

i. Mengukur tahap kemahiran membuat keputusan dan daya tahan dalamkalangan PPB.

ii. Mengenal pasti hubungan antara kemahiran membuat keputusan dan daya tahan.

\section{Kajian Literatur}

\section{Kemahiran membuatkeputusan}

Rehman \& Khan (2015) telah mendefinisikan membuat keputusan sebagai proses memilih satu kemungkinan daripada kemungkinan yang lain. Membuat keputusan juga merupakan satu kemahiran yang melibatkan proses kognitif yang kritikal dan ia digunakan dalam apa jua situasi dalam kehidupan 
seharian (Zakri\& Saemah, 2015). Di samping itu, kemahiran ini merupakan kemahiran yang boleh dipelajari serta diasah (Mincemoyer \& Perkins, 2003; Klaczynski et al., 2001) dan mampu menyumbang kepada peningkatan penghargaan kendiri, kepuasan hidup serta kebolehan menangani tekanan hidup (Colakkadioglu, 2016).

Kajian mengenai kemahiran membuat keputusan dalam kalangan PPB telah dijalankan secara agresif di barat. Namun, di Malaysia kajian khusus berkaitan kemahiran ini belum meluas. Walau bagaimana pun, daripada kajian- kajian mengenai PPB di Malaysia seperti kajian terhadap tahap kepimpinan (Rorlinda, 2014), kemahiran sosial (Noriah, Mohd Hakimie \& Abu Yazid, 2014), profil pemprosesan kognitif (Rosadah et al., 2005) telah menjelaskan secara umumnya tahap kemahiran membuat keputusan dalam kalangan PPB adalah tinggi. Begitu juga dengan kajian di luar negara, kebanyakan pengkaji menjelaskan kemahiran membuat keputusan golongan ini adalah tinggi (Saygili, 2014; Ball et al., 1994; Davidson \& Sternberg, 1984).

Walau bagaimanapun, terdapat juga banyak kajian yang mencadangkan PPB perlu dipertingkatkan tahap kemahiran tersebut (Ozcan \& Zaaroglu, 2017; Mofield et al., 2016; Milligan, 2004). Sementara, Schlichter (1981) turut melihat kepentingan kemahiran membuat keputusan dalam kalangan PPB bagi mengimbangi aspek keperluan dan kebolehan mereka seterusnya beliau berpendapat kemahiran ini perlu disemai terhadap golongan ini. Ia juga bertepatan dengan konsep kemahiran itu sendiri iaitu boleh diajar, diasah serta digilap (Mincemoyer \& Perkins, 2003) yang seterusnya menjadikan kemahiran keputusan sebagai satu tuntutan kepada golongan ini.

Di samping itu, Ersoy \& Deniz (2016) menjelaskan kemahiran membuat keputusan dalam kalangan PPB perlu diasah secara berterusan kerana ciri-ciri unik yang dimiliki oleh PPB itu sendiri mampu membuatkan kemahiran tersebut menjadi lemah. Sebagai contoh, salah satu ciri istimewa PPB adalah kesempurnaan melampau. Ciri tersebut telah meletakkan golongan ini dalam keadaan tekanan atau marah sekiranya mereka tidak dapat melakukan sesuatu perkara dengan sempurna sebagai mana yang dijangkakan. Ciri kesempurnaan tersebut telah mendorong PPB untuk tidak memikirkan lagi mengenai alternatif dalam mengambil keputusan sebaliknya terus bertindak tanpa memikirkan perbezaan di antara yang betul dan salah. Perkara tersebut menjelaskan, walaupun kebanyakan berpendapat kemahiran membuat keputusan dalam kalangan PPB adalah tinggi, namun perlu diberi perhatian bahawa kemahiran tersebut mampu tergugat. Oleh itu, kemahiran itu perlu disemai dari masa ke masa.

\section{Daya tahan}

Daya tahan dalam diri seseorang mampu bertindak sebagai benteng pertahanan daripada terus jatuh apabila terdedah dengan kesukaran atau tekanan hidup. Menurut Fredrickson (2004), daya tahan adalah satu keupayaan bagi seseorang individu untuk bangkit daripada kesedihan atau kesukaran. Malahan, individu tersebut juga akan pulih dengan melantun kembali segala kesukaran yang dihadapi dan mampu untuk terus berkembang maju (Chen et al. 2017).

Sementara itu, Neihart (2002) mencadangkan ciri-ciri pelajar pintar adalah sebagaimana ciri-ciri pelajar yang berdaya tahan tinggi. Mereka lebih cenderung untuk memiliki tahap yang tinggi dari aspek kecerdasan emosi, efikasi kendiri, sikap ingin tahu, kebolehan menyelesaikan masalah dan sebagainya. Manakala, Cazan \& Dumitrescu (2016) pula berpendapat PPB yang berdaya tahan adalah pelajar yang mampu menangani cabaran-cabaran dalam kehidupan. Selain itu, mereka turut menjadikan segala kesukaran hidup sebagai satu cabaran dalam diri tanpa melihat perkara tersebut sebagai satu masalah atau pun halangan untuk lebih maju. Walaupun kebanyakan kajian mengenai PPB menjelaskan golongan ini memiliki daya tahan yang tinggi, namun Bland et al. (1994) mendedahkan terdapat juga PPB yang rendah dari aspek daya tahan. Perkara ini bukan sahaja menjadi satu kerugian yang besar bagi diri PPB itu sendiri malahan turut merugikan negara kerana PPB merupakan aset terpenting negara. Bersesuaian dengan pendapat Noriah dan Abu Yazid (2010) PPB merupakan aset terpenting negara yang perlu dicungkil potensi kecemerlangan mereka bagi perkembangan negara. Justeru, Bland et al. (1994) menegaskan akan kepentingan kajian mengenai daya tahan dalam kalangan PPB. 
Dalam pada itu, Pfeiffer \& Stocking (2000) turut berpendapat walaupun PPB lebih cenderung untuk mempamerkan kebolehan dalam akademik serta lebih dikenali sebagai pelajar yang cekap dalam menyelesaikan masalah dan kreatif, mereka turut terdedah dengan pengalaman kesakitan, kesukaran serta masalah-masalah psikologi. Perkara tersebut disokong oleh dapatan daripada kajian Kline and Short (1991) yang mendapati tahap daya tahan pelajar pintar adalah berkadar songsang dengan tahap masalah emosi. Beliau turut mendedahkan, tahap daya tahan PPB semakin menurun apabila meningkatnya gred kedudukan kelas disebabkan oleh peningkatan masalah emosi dalam kalangan mereka.

\section{Metod Kajian}

Kajian ini adalah kajian kuantitatif yang melibatkan analisis deskriptif dan juga inferensi. Kajian tinjauan ini terdiri daripada PPB yang dikenal pasti melalui Program PERMATA Insan yang mendapat pendidikan di Kolej GENIUS Insan seramai N=188 orang (lelaki 92, perempuan 96). Kolej GENIUS Insan adalah satu-satunya kolej dalam universiti yang menempatkan PPB bagi Program PERMATA Insan yang bersandarkan kepada integrasi aqli \& naqli bertujuan untuk melahirkan golongan cendekiawan dan pemimpin Islam. Alat kajian Assessing Decision Making Skills (ADMS) oleh Mincemoyer \& Perkins (2003) yang telah diterjemahkan oleh Zakri (2014) telah digunakan untuk mengukur tahap membuat keputusan. Soal selidik ini mengandungi 19 item yang terdiri daripada lima komponen dalam membuat keputusan iaitu kemahiran mendefinisikan masalah, kemahiran menjana alternatif, kemahiran menyemak risiko dan akibat, kemahiran memilih alternatif dan kemahiran menilai keputusan. Setiap item mengandungi pilihan jawapan menggunakan skala semantik iaitu 1 (tidak pernah) hingga 5 (sentiasa). Manakala, bagi mengukur tahap daya tahan pula, Skala Daya Tahan Remaja (SDTR) yang digubal oleh Biscoe dan Hariss (1994) telah digunakan. Soal selidik ini telah diterjemahkan ke Bahasa Melayu oleh Ibrahim (2011). Jumlah item dalam SDTR ialah sebanyak 67 item, iaitu 34 item positif dan 33 item negatif. Pemarkahan diukur berdasarkan skala likert lima mata iaitu skala 1-5 (sangat tidak setuju hingga sangat setuju). SDTR mengukur daya tahan dengan tujuh sub skala iaitu celik akal, sifat berdikari, corak perhubungan, inisiatif diri, kreativiti dan humor, moraliti dan ketabahan diri. Data dianalisis secara deskriptif bagi mengukur tahap membuat keputusan dan daya tahan dan analisis korelasi dijalankan untuk mengenal pasti hubungan antara kemahiran membuat keputusan dan daya tahan.

\section{Dapatan dan Perbincangan}

Data dikumpulkan dan dianalisis menggunakan perisian Statistical Package for Social Studies (SPSS) versi 23. Jadual 1 dan jadual 2 menunjukkan dapatan analisis deskriptif terhadap sampel keseluruhan sebanyak 188 bagi pemboleh ubah kemahiran membuat keputusan dan daya tahan adalah pada tahap sederhana.

Jadual 1: Tahap Kemahiran Membuat Keputusan

\begin{tabular}{lll}
\hline Pemboleh ubah / subskala & Tahap & Keseluruhan \\
\hline Kemahiran membuat keputusan & Rendah & $25.0 \%$ \\
& Sederhana & $50.2 \%$ \\
Sub skala mendefinisikan masalah & Tinggi & $24.8 \%$ \\
& Rendah & $39.4 \%$ \\
& Sederhana & $31.4 \%$ \\
Sub skala kemahiran menjana alternatif & Tinggi & $29.3 \%$ \\
& Rendah & $37.8 \%$ \\
& Sederhana & $33.5 \%$ \\
Sub skala kemahiran menyemak risiko dan & Tinggi & $28.7 \%$ \\
akibat & Rendah & $35.6 \%$ \\
& Sederhana & $42.0 \%$ \\
\hline
\end{tabular}


DOI: https://doi.org/10.47405/mjssh.v5i12.601

\begin{tabular}{lll}
\hline & Tinggi & $22.3 \%$ \\
Sub skala kemahiran memilih alternatif & Rendah & $27.1 \%$ \\
& Sederhana & $56.9 \%$ \\
& Tinggi & $16.0 \%$ \\
Sub skala kemahiran menilai keputusan & Rendah & $28.8 \%$ \\
& Sederhana & $48.4 \%$ \\
& Tinggi & $22.8 \%$ \\
\hline
\end{tabular}

Jadual 2: Tahap Daya Tahan

\begin{tabular}{lll}
\hline Pemboleh ubah / subskala & Tahap & Keseluruhan \\
\hline Daya tahan & Rendah & $8 \%$ \\
& Sederhana & $92 \%$ \\
Sub skala celik akal & Tinggi & - \\
& Rendah & 14.9 \\
Sub skala berdikari & Sederhana & 85.1 \\
& Tinggi & - \\
Sub skala corak perhubungan & Rendah & $14.4 \%$ \\
& Sederhana & $85.6 \%$ \\
& Tinggi & - \\
Sub skala inisiatif diri & Rendah & $17.6 \%$ \\
& Sederhana & $82.4 \%$ \\
Sub skala kreativiti \& humor & Tinggi & - \\
& Rendah & $24.4 \%$ \\
& Sederhana & $75.5 \%$ \\
Sub skala moral & Tinggi & - \\
& Rendah & $32.5 \%$ \\
& Sederhana & $67.6 \%$ \\
Sub skala ketabahan diri & Tinggi & - \\
& Rendah & $18.6 \%$ \\
& Sederhana & $81.4 \%$ \\
& Tinggi & - \\
\hline & Rendah & $47.9 \%$ \\
& Sederhana & $52.1 \%$ \\
\hline
\end{tabular}

Jadual 3 menunjukkan nilai pekali Pearson r adalah .857 iaitu satu nilai positif yang kuat dan nilai ini adalah signifikan $(\mathrm{p}<0.05)$. Nilai $\mathrm{r}$ ini menunjukkan wujud hubungan positif yang kuat dan signifikan antara kemahiran membuat keputusan dan daya tahan, $r=857, \mathrm{n}=188, \mathrm{p}<0.05$.

Jadual 3: Hubungan antara Kemahiran Membuat Keputusan dan Daya Tahan

\begin{tabular}{lll}
\hline Kategori & & Daya Tahan \\
\hline $\begin{array}{l}\text { Kemahiran Membuat } \\
\text { Keputusan }\end{array}$ & Korelasi Pearson & $.857^{* *}$ \\
& Sig. (2-tailed) & .000 \\
\hline
\end{tabular}

Keputusan analisis deskriptif menjelaskan lebih daripada separuh daripada PPB di Kolej Genius Insan memiliki tahap yang sederhana bagi kemahiran membuat keputusan manakala hampir kesemua pelajar 
didapati memiliki tahap yang sederhana bagi daya tahan. Bagi pemboleh ubah kemahiran membuat keputusan, dapatan berlawanan dengan kajian lepas yang mendapati tahap kemahiran membuat keputusan PPB adalah tinggi (Saygili, 2014; Ball et al., 1994; Davidson \& Sternberg, 1984). Walau bagaimanapun, dapatan kajian ini bertepatan dengan pendapat beberapa pengkaji lepas yang mencadangkan tahap kemahiran membuat PPB perlu dipertingkatkan (Ozcan \& Zaaroglu, 2017; Mofield et al., 2016; Milligan, 2004). Ini kerana golongan PPB ini mempunyai potensi untuk berkembang ke tahap yang optimum dan mereka sepatutnya memiliki tahap kemahiran membuat keputusan yang cemerlang selaras dengan kepintaran semula jadi yang dimiliki (Gagne, 2011). Tambahan lagi, Ersoy dan Deniz (2016) dalam kajiannya turut menegaskan kemahiran membuat keputusan dalam kalangan PPB perlu diasah secara berterusan kerana ciri-ciri unik yang dimiliki oleh PPB itu sendiri mampu membuatkan kemahiran tersebut menjadi lemah.

Analisis mengikut sub skala turut menjelaskan kebanyakan pelajar Program PERMATA Insan mencatatkan tahap yang rendah bagi sub skala mendefinisikan masalah iaitu sebanyak $39.4 \%$ diikuti dengan tahap sederhana $31.4 \%$ dan tahap tinggi adalah sebanyak $29.3 \%$. Begitu juga bagi sub skala menjana alternatif, kebanyakan pelajar mencatatkan tahap yang rendah iaitu 37.8\%, diikuti dengan tahap sederhana $33.5 \%$ dan tahap tinggi adalah $28.7 \%$. Kedua-dua sub skala ini merupakan kemahiran yang paling tidak berjaya dikuasai oleh pelajar berbanding dengan sub skala lain. Menurut Adair (2009), kelemahan aspek ini menggambarkan individu tersebut sukar memastikan arah tujuan hidup serta mempunyai kelemahan dari aspek mengumpul maklumat yang relevan berkaitan dengan membuat keputusan. Dapatan tersebut dipengaruhi oleh ciri-ciri unik PPB itu sendiri. Bertepatan dengan kajian yang dijalankan oleh Ersoy dan Deniz (2016) mendapati ciri unik PPB seperti ketidakselarasan perkembangan, sikap kesempurnaan melampau dan jangkaan yang tinggi daripada masyarakat telah menggugat dan memberi limitasi terhadap keupayaan membuat keputusan dalam kalangan PPB. Di samping itu, dapatan tersebut turut mendedahkan PPB bagi Program PERMATA Insan juga sukar menangani isu sosial dan emosi. Ini kerana, elemen membuat keputusan adalah diperlukan dalam usaha membantu PPB berhadapan dengan isu sosial yang dihadapi (Mofield et al., 2016; Milligan, 2004; Ozcan, 2017; Schlichter, 1981).

Bagi daya tahan pula, dapatan kajian ini berlawanan dengan kajian seperti Choven dan Freeman (1993) dan Oden (1968) yang mendapati golongan PPB adalah tinggi aspek daya tahan mereka. Namun, Bland et al. (1994) mendapati terdapat juga PPB yang rendah dari aspek daya tahan. Sementara, kajian-kajian lain pula melihat tahap daya tahan PPB adalah sebagaimana tahap daya tahan pelajar normal biasa (Lopez \& Sotillo, 2009; Martin, Burns \& Schonlau, 2010; Neihart et al., 2002). Menurut Teori Resilien oleh Wolin \& Wolin (1993), terdapat enam faktor yang mendorong seseorang individu untuk memiliki daya tahan dalam kehidupan. Faktor tersebut adalah celik akal, corak perhubungan, sikap berdikari, inisiatif diri, kreatif \& humor dan moral. Kajian-kajian seperti Neihart (2001), Choven dan Freeman (1993) serta Oden 1968) menyatakan elemen tersebut tinggi dalam kalangan PPB. Namun, berdasarkan kepada dapatan kajian ini, kebanyakan PPB bagi Program PERMATA Insan berada pada tahap yang sederhana bagi semua faktor tersebut serta terdapat juga segelintir daripada mereka adalah pada tahap yang rendah. Dapatan ini menjelaskan, ciri unik PPB telah menghalang perkembangan faktor daya tahan dalam kalangan mereka. Bertepatan dengan kajian Chen et al. (2017) dan Kim (2015) yang mendapati ciri unik PPB seperti ketidakselarasan perkembangan serta sikap kesempurnaan melampau telah memberi kesan terhadap keupayaan daya tahan PPB.

Selain itu, kajian ini juga selari dengan kajian-kajian lepas yang mendapati kemahiran membuat keputusan mempunyai perhubungan dengan daya tahan (Coscun et al., 2014). Membuat keputusan adalah salah satu proses asas kognitif bagi tingkah laku individu (Wang \& Ruhe, 2007). Begitu juga dengan daya tahan yang turut membabitkan elemen kognitif dalam menyumbang kepada ketahanan diri menghadapi kesukaran. Parsons, Kruijt dan Fox (2016) dalam kajiannya menjelaskan kelemahan dalam kefungsian kognitif seperti kemampuan memberi perhatian, mencabar pemikiran dan idea serta kegagalan mengubah set mental menyumbangkan kelemahan dalam daya tahan. Di samping itu, memiliki kemahiran membuat keputusan juga menyumbang kepada daya tahan dalam diri individu (Diker \& Tosun, 2014). Oleh itu, melihat kepada fungsi kemahiran membuat keputusan dan daya tahan sebagai elemen dalam membantu PPB menangani isu sosial dan emosi menjadikan kedua-dua 
indikator tersebut perlu dipupuk dan ditingkatkan dalam kalangan PBB. Justeru, dengan mengenal pasti tahap kemahiran membuat keputusan dan daya tahan PPB dapat membantu merancang strategi intervensi yang sesuai.

Implikasi daripada kajian ini adalah keperluan untuk memfokuskan kepada peningkatan kemahiran membuat keputusan dan daya tahan dalam kalangan PPB dalam usaha membantu mereka menguruskan isu sosial dan emosi yang dialami. Dalam memberi perkhidmatan yang berkesan, kaunselor bertanggungjawab memberikan perkhidmatan yang selari dengan ciri-ciri unik PPB. Dicadangkan para kaunselor untuk mengaplikasikan pendekatan terapi bermain dalam memberi perkhidmatan kerana elemen yang terkandung dalam pendekatan terapi bermain mempunyai persamaan dengan ciri-ciri PPB dari aspek kreativiti (Rorlinda et al., 2016), imaginasi, fantasi, sensitif (Rosselet \& Stauffer, 2013; Sak, 2004) yang seterusnya dapat memenuhi keperluan PPB (Rosselet \& Stauffer, 2013).

\section{Kesimpulan}

Kesimpulannya, perbincangan kajian ini menjelaskan kemahiran membuat keputusan dan daya tahan merupakan elemen yang dapat membantu PPB dalam usaha menangani isu sosial dan emosi yang dihadapi dan elemen tersebut boleh dipelajari dan diasah serta dipertingkatkan melalui satu kaedah yang sistematik. Menurut Coscun et al. (2014) pemboleh ubah kemahiran membuat keputusan mempunyai perkaitan yang rapat dengan pemboleh ubah daya tahan. Individu yang memiliki kemahiran membuat keputusan yang tinggi juga memiliki tahap daya tahan yang tinggi. Sebaliknya, mereka yang rendah kemahiran membuat keputusan sukar untuk menangani segala isu yang dihadapi dengan baik serta tidak mempunyai keupayaan untuk terus bangkit. Oleh yang demikian, kaunselor perlu memainkan peranan dalam usaha membantu PPB bagi meningkatkan kemahiran dan kebolehan tersebut dalam menangani isu sosial dan emosi secara berkesan. Medium perkhidmatan yang sesuai bagi PPB adalah perkhidmatan bimbingan kaunseling, di mana PPB dapat mengasah kemahiran serta celik akal daripada perkhidmatan tersebut.

Melihat kepada kepentingan dalam meningkatkan kemahiran membuat keputusan dan daya tahan dalam kalangan PPB serta ciri-ciri unik golongan ini, adalah menjadi keperluan untuk mengenal pasti pendekatan perkhidmatan yang sesuai diaplikasikan terhadap golongan ini. Oleh itu, kajian berkaitan pendekatan yang sesuai bagi PPB harus diketengahkan oleh pengkaji akan datang dalam usaha meningkatkan kemahiran membuat keputusan dan daya tahan mereka. Di samping itu, adalah dicadangkan pendekatan yang kreatif seperti pendekatan terapi bermain harus diketengahkan dalam usaha membantu PPB memandangkan pendekatan terapi bermain kaya dengan elemen kreatif (Sarpoulaki \& Kolahi, 2016). Perkara tersebut juga bersesuaian dengan pandangan Moon (2002) yang menggalakkan kaunselor untuk meneroka teknik atau strategi yang berkesan untuk diaplikasikan kepada PPB. Malahan penggabungan teori kaunseling dengan pelbagai terapi yang sesuai membolehkan klien mendapat celik akal dengan lebih cepat (Paw, Noriah \& Salleh, 2008).

Usaha dan cadangan yang telah dibincangkan di atas dilihat sebagai salah satu strategi yang berkesan dalam menangani isu sosial dan emosi dalam kalangan PPB. Ia bukan sahaja membantu memperbaiki tahap kehidupan PPB yang dikategorikan dalam remaja berkeperluan khas malah mengembangkan peranan perkhidmatan bimbingan dan kaunseling di sekolah dalam membantu PPB. Justeru, kajian ini diharap dapat memberi kesedaran kepada masyarakat mengenai isu-isu yang dialami oleh PPB serta memberi pendedahan kepada pihak pengamal profesional terutamanya kaunselor mengenai strategi pengurusan terhadap isu sosial dan emosi dalam kalangan PPB.

\section{Rujukan}

Abu Yazid Abu Bakar \& Noriah Mohd Ishak. (2016). Pendidikan pintar dan berbakat di Malaysia. Penerbit Universiti Kebangsaan Malaysia. Bangi. 
Abu Yazid, A.B. \& Aliza, A. (2009). Sokongan psikologikal dan sosio-emosi pelajar pintar cerdas. In Noriah M.I., Rosadah A.M. \& Siti Fatimah M.Y. (Eds.), PERMATApintar: Pengalaman UKM. Bangi: UKM.

Aliza Alias \& Hamidah Yamat. (2009). Ciri-ciri kanak-kanak pintar cerdas. PERMATApintar Negara: Pengalaman UKM. Bangi: Pusat PERMATApintar Negara.

American School Counselor Association. (2005). The ASCA National Model: A framework for school counseling programs (2nd ed.). Alexandria, VA: Author.

Ball, C. Mann, L. \& Stamm, C. (1994). Decision-Making Abilities of Intellectually Gifted, Australian Journal of Psychology, 46(1), 13-20.

Bland, L. C. Sowa, C. J. \& Callahan, C. M. (1994). An Overview of Resilience in Gifted Children. Roeper Review, 17(2), 77-80.

Cazan, A. \& Dumitrescu, S. A. (2016). Exploring The Relationship Between Adolescent Resilience, Self-Perception And Locus Of Control. Romanian Journal of Experimental Applied Psychology, 7(1), 283-286.

Chen, X. Cheung, H. Y. Fan, X. \& Wu, J. (2017). Factors related to resilience of academically gifted students in the chinese cultural and educational environment. Psychology in the Schools, 1, 1-13.

Colakkadioglu, O. \& Celik, B. (2016). The effect of decision-making skill training programs on selfesteem and decision-making styles. Eurasian Journal of Educational Research, 65, 259-276.

Colangelo, N. (2002). Counseling gifted and talented students. The National Research Center on the Gifted and Talented Newsletter. Retrieved from http://www.gifted.uconn.edu/nrcgt/newsletter/fall02/fall022.html.

Coskun, Y.D. Garipağaoğlu.C. \& Tosun, U. (2014). Analysis of the Relationship between the Resiliency Level and Problem Solving Skills of University Students. Procedia - Social and Behavioral Sciences, 114, 673-680.

Davidson, J \& Sternberg, R. (1984). The role of insight in intellectual giftedness. Gifted Child Quarterly, 28, 58-64.

Ersoy, E. \& Deniz, M. E. (2016). Psychometric Properties of the Gifted Students' Coping with Anger and Decision Making Skills Scale. Journal of Education and Practice, 7(15), 121-128.

Fouladchang, M. Kohgard, A. \& Salah, V. (2010). A study of psychological health among students of gifted and nongifted high schools. Procedia - Social and Behavioral Sciences, 5(2), 1220-1225.

Frederickson, B. L. (2004). The Broaden-and-Build Theory of Positive Emotions. Philosophical Transactions of the Royal Society, 359, 1367-1377.

Java, L. A. (2014). "Problem Solving Strategies and Metacognitive Skills for Gifted Students in Middle School" Retrieved from https://digitalcommons.lsu.edu/gradschool_theses/1872.

Klaczynski, P. A. Byrnes, J. B. \& Jacobs, J. E. (2001). Introduction: Special issue on decision making. Journal of Applied Developmental Psychology, 22, 225-236.

Kline, B. E. \& Short, E.B. (1991). Changes in emotional resilience: Gifted adolescent females. Roeper Review, 13(3), 118-121.

Mann. R.L. (2006). Effective Teaching Strategies for Gifted/Learning-Disabled Students With Spatial Strengths. The Journal of Secondary Gifted Education, XVII(2). 112-121.

Milligan, J. (2004). Leadership Skills of Gifted Students in a Rural Setting: Promising Programs for Leadership Development. Rural Special Education Quarterly, 23(1), 16-21.

Mincemoyer, C.C. \& Perkins, D.F. (2003). Assessing decision making skills of youth. The Forum for Family and Consumer Issues, 8(1).

Mofield, E. Parker Peters, M.,\& Chakraborti-Ghosh, S. (2016). Perfectionism, Coping, and Underachievement in Gifted Adolescents: Avoidance vs. Approach Orientations. Education Sciences, 6(3), 21.

Mofield. E. L (2010) Addressing Multidimensional Perfectionism in Gifted Adolescents with Affective Curriculum. Journal for the Education of the Gifted, 33(4), 479-513.

Moon, S.M. Kelly, K.R. \& Feldhusen (1997). Specialized counseling services for gifted youth and their families: A needs assessment. Gifted Child Quarterly, 41, 16-25.

Morawska, A. \& Sanders, M. R. (2009). Parenting Gifted and Talented Children: Conceptual and Empirical Foundations. Gifted Child Quarterly, 53, 163-17.

Neihart, M. (2002). Risk and resilience in gifted children: A conceptual framework. In M. Neihart, S. Reis, N.M. Rob- inson, \& S.M. Moon (Eds.), The social and emotional development of gifted children: What do we know? (pp. 113-124). Waco, Texas: Prufrock Press, Inc. 
Noriah Mohd Ishak \& Abu Yazid Abu Bakar. (2010). Psychological issues and the need for counseling services among Malaysian gifted students. Procedia - Social and Behavioral Sciences, 5(2), 665-673.

Noriah. M. I, Mohd Hakimie. Z. A, Abu Yazid. A. B. (2014). Dimensions of Social Skills and their Relationship with Empathy among Gifted and Talented Students in Malaysia. Procedia - Social and Behavioral Sciences, 116(2003), 750-753.

Ozcan. D, Zaaroglu, L. (2017). Determination of The Relationship Between Strategies of DecisionMaking And Emotional Intelligence Of Gifted Students. ENSAYOS, Revista de la Facultad de Educación de Albacete, 32(2).

Peterson, J.S. (2006). Addressing counseling needs of gifted students. Professional School Counseling, 10(1), 43-51.

Pfeiffer, S. I., \& Stocking, V. B. (2000). Vulnerabilities of academically gifted students. Special Services in the Schools, 16(1-2), 83-93.

Rafidah Kastawi \& Noriah Mohd Ishak. (2013). Terapi seni dalam kaunseling pelajar pintar dan berbakat. Malaysian Journal of Youth Studies, 8(6), 147-166.

Rehman, R. R. \& Khan, A. W. (2015). Realting individual demographics, work- family conflict and decision making styles of faculity members in higher education sector of Pakistan. VFAST Transections on Education and Social Sciences, 5, 51-63.

Renzulli, J. S. (1978). What Makes Giftedness? Re-examining a Definition. Phi Delta Kappa 60: 180181.

Rorlinda Yusuf. (2014). Ciri- ciri kepimpinan pelajar pintar dan berbakat: Implikasi ke atas kepimpinan remaja Islam. International Journal of Islamic Thought, 6, 57-70.

Rorlinda Yusuf, Noriah Mohd Ishak, Siti Aishah Hassan \& Afifah Mohd Radzi. (2016). Kajian Jatidiri dan Tekanan Isu Sosio-Emosi dalam Kalangan Pelajar Pintar dan Berbakat. Jurnal Psikologi Malaysia, 30(2), 42-60.

Rosadah Abd Majid, Noriah Mohd Ishak, \& Melor Md Yunus. (2009). Kepintaran dan pintar cerdas berbakat: Definisi dan makna. Dalam PERMATApintar Negara: Pengalaman UKM. Pusat PERMATApintar Negara. Universiti KebangsaanMalaysia. Bangi.

Rosadah Abd Majid, Noriah Mohd Ishak, Zalizan Mohd Jelas. (2005) Profil pemprosesan kognitif pelajar pintar cerdas akademik di sekolah menengah. Jurnal Pendidikan Malaysia, 30, 35-49.

Saygili, G. (2014). Problem-Solving Skills Employed by Gifted Children and Their Peers in Public Primary Schools in Turkey. Society for Personality Research, 42, 53-64.

Schlichter, C.L. (1981). Decision Making: An Instructional Strategy for the Rural Gifted Student. Retrieved from http://files.eric.ed.gov/fulltext/ED220257.pdf.

Scott, M. T. (2012). Socio-Emotional and Psychological Issues and Needs of Gifted African-American Students: Culture Matters. Interdisciplinary Journal of Teaching and Learning, 2(1), 23-33.

Siti Fatimah. M. Y, Noriah. M.I, Melor. M.Y, Rosadah. A.M (2012), The Identification of Gifted and Talented Students. Procedia - Social and Behavioral Sciences, 55, 585 - 593.

Touron, J. Touron, Silvero, M. (2005). The Center for Talented Youth Spain: An initiative to serve highly able students. High Ability, 15, 121-135.

Versteynen, L. (2013). Issues in the social and emotional adjustment of gifted children: What does the literature say?. The New Zealand Journal of Gifted Education, 13(1).

Wood, S. (2010). Best practices in counseling the gifted in school: What's really happening. Gifted Child Quarterly, 54(1), 42-58.

Zaffrann, R. T., \& Colangelo, N. (1977). Counseling with Gifted and Talented Students. Gifted Child Quarterly, 21, 305-321.

Zakri Abdullah \& Saemah Rahman. (2015). Kemahiran Meta-Tingkah Laku dan Kemahiran Membuat Keputusan Pelajar Bermasalah Disiplin dan Tidak Bermasalah Disiplin. Jurnal Pendidikan Malaysia, 40(2), 175-183. 